PROF. PHILLIP WARWICK (Orcid ID : 0000-0001-8774-5125)

Article type : Original Article

\title{
A New Reference Material for Tritium Organic Molecules in Sediment: Results of an International Intercomparison Exercise
}

\author{
Phillip E. Warwick (1)*, Ian W. Croudace (1), Richard M. Marsh (1), N. Baglan (2) and
} Sangbok B. Kim (3)

(1) GAU-Radioanalytical Laboratories, University of Southampton, National Oceanography Centre, Southampton, SO14 3ZH, UK

(2) CEA/DAM/DIF, F91297 Arpajon, France

(3) CNL, Chalk River Laboratories, Chalk River, Ontario, Canada, K0J 1J0

*Corresponding author. e-mail: phil.warwick@noc.soton.ac.uk

Solid matrix ${ }^{3} \mathrm{H}$ reference materials are challenging to prepare given the volatile nature of ${ }^{3} \mathrm{H}$ and are often unrepresentative of the range of ${ }^{3} \mathrm{H}$ forms that may be encountered during routine analysis. As a result, few ${ }^{3} \mathrm{H}$ reference materials are currently available, undermining verification of analytical techniques for environmental ${ }^{3} \mathrm{H}$ measurement. To address this, an International Working Group on Organically-Bound Tritium Analysis determined to produce a tritium natural matrix reference material (NMRM). The reference material comprises marine sediment blended with sewage sludge contaminated with ${ }^{3} \mathrm{H}$-organic species arising from authorised discharges from a radiopharmaceutical manufacturing site. Previous studies have demonstrated that the ${ }^{3} \mathrm{H}$ species have persisted in the environment over three decades providing valuable supporting data to underpin the characterisation of the NMRM. The preparation and characterisation of the NMRM is described along with the subsequent application of the reference material in an international

This article has been accepted for publication and undergone full peer review but has not been through the copyediting, typesetting, pagination and proofreading process, which may lead to differences between this version and the Version of Record. Please cite this article as doi: 10.1111/ggr.12207

This article is protected by copyright. All rights reserved. 
intercomparison exercise involving nineteen laboratories from nine countries. A reference value of $168 \pm 22 \mathrm{~Bq} \mathrm{~kg}^{-1}$ was derived from the data arising from the proficiency test.

Keywords: tritium, organically-bound tritium, sediment, natural matrix reference material, intercomparison.

Tritium $\left({ }^{3} \mathrm{H}\right)$ is a low energy beta-emitting radioisotope of hydrogen that is produced naturally via cosmic ray interactions in the upper atmosphere. The radionuclide has also been released in significant quantities into the environment as a result of nuclear weapons' testing, nuclear accidents and authorised releases from nuclear fission and fusion power plants, nuclear weapons' manufacturing facilities, radioluminescent device manufacture / decommissioning and radiopharmaceutical manufacture. Although predominantly present as water $\left({ }^{1} \mathrm{H}^{3} \mathrm{HO}\right),{ }^{3} \mathrm{H}$ can also be incorporated into organic molecules, significantly modifying its behaviour in the environment and in humans (Diabaté and Strack 1993, Kim et al. 2013). Where this incorporation is as a result of technological operations, the form of ${ }^{3} \mathrm{H}$ is referred to as a 'tritium organic molecule' (TOM). This is in contrast to ${ }^{3} \mathrm{H}$ incorporated into organic molecules via biological processes, which is termed 'organically-bound tritium', OBT (Kim et al. 2013). TOMs may subsequently be more effectively incorporated into biomolecules and, along with OBT, exhibit an increased biological half life when compared with tritiated water $\left({ }^{1} \mathrm{H}^{3} \mathrm{HO}\right)$. A higher effective dose coefficient is therefore potentially associated with this form of ${ }^{3} \mathrm{H}$ (DeVol and Powell 2004). The assessment of organic associated ${ }^{3} \mathrm{H}$ in the environment for regulatory purposes has become more widespread over the past decade. Organic ${ }^{3} \mathrm{H}$ in sediments was identified as being of particular significance when considering contaminant sinks and the long-term persistence of ${ }^{3} \mathrm{H}$ in the environment arising from discharges associated with radiopharmaceutical production (Croudace et al. 2012). Planned expansion of pressurised water reactors (PWRs), including installations at Flammanville, France, Olkiluoto 3, Finland and Hinkley Point C, UK, and heavy water reactor (PHWR) installations (notably in India) will give rise to ${ }^{3} \mathrm{H}$ discharges and require robust ${ }^{3} \mathrm{H}$ monitoring capability. Analytical methods for the determination of ${ }^{3} \mathrm{H}$ in a range of solid and liquid matrices are therefore required but must be underpinned by validation using environmentally-relevant reference materials and not simply laboratory-spiked matrices. Techniques for the determination of ${ }^{3} \mathrm{H}$ in environmental samples are well established (e.g., Baglan et al. 2012) however, only a limited number of intercomparison exercises focussing on TOM / OBT have been reported (e.g., Kim et al. 2015). In addition, the availability of suitable natural matrix reference materials (NMRMs) for method validation and quality control purposes are limited. This is partly due to the challenges in preparing stable TOM NMRMs that are representative of the materials encountered during monitoring programmes. As part of a recently formed International Working Group on OBT (Baglan et al. 2012) a need for such NMRMs was confirmed. It was agreed to address the current shortage through a series of intercomparison exercises organised by the working group, with exercises focussing on OBT reference materials for potato, sediment, wheat and grass (Baglan et al. 2015). GAU-Radioanalytical had previously investigated the significance of ${ }^{3} \mathrm{H}$ speciation in determining its stability in decommissioning (Kim et al. 2008) and environmental (Croudace et al. 2012) matrices and had demonstrated that the radiopharmaceutical-derived TOM record in Severn Estuary sediments was preserved over a 30 year

This article is protected by copyright. All rights reserved. 
timescale (Croudace et al. 2012). Based on this identified stability, it was proposed to use radiopharmaceutical discharge-derived materials to prepare a stable TOM-in-sediment NMRM. Such materials contain a complex mixture of ${ }^{3} \mathrm{H}$-labelled organic molecules and by-products arising from radiopharmaceutical synthesis. Although specific identification of the organic molecules present has not been performed, the species are known to be particle reactive and to persist in the particle phase for considerable periods. The TOMs present are also comparable to those discharged into the Severn Estuary and which ultimately associate with marine sediments. Previous studies (Warwick et al. 2010) have demonstrated that thermal desorption profiles for ${ }^{3} \mathrm{H}$ associated with the sewage sludge differ significantly from those observed for ${ }^{1} \mathrm{H}^{3} \mathrm{HO}$-contaminated materials, with higher temperatures required to effectively liberate the ${ }^{3} \mathrm{H}$. They therefore represent a significant challenge for radioanalytical procedures when compared with ${ }^{1} \mathrm{H}^{3} \mathrm{HO}$ or simple ${ }^{3} \mathrm{H}$ organic species and are useful as a reference material. GAU-Radioanalytical (Southampton, UK) produced and characterised a marine sediment NMRM containing an activity per unit mass of TOMs (nominally $170 \mathrm{~Bq} \mathrm{~kg}^{-1}$ ) that was designed to be useful as a QC RM for radioanalytical chemists working in environmental and nuclear decommissioning sectors. Details of the sediment NMRM preparation and characterisation and results of an intercomparison exercise are reported in this paper.

\section{Methods}

The characterisation of the sediment TOM NMRM and the assessment of proficiency test data were undertaken following the approach detailed in ISO 13528-2015. The objective of the proficiency test was to compare a laboratory's results with a group of results obtained from other participants in the same round. The limits for the proficiency test are derived from the distribution of the participants' results.

\section{Preparation of proficiency test sediment}

The reference material was prepared by serial dilution of a ${ }^{3} \mathrm{H}$-contaminated sewage sludge with marine sediment (Figure 1). Bulk marine sediment was collected from an estuarine intertidal environment and refrigerated prior to processing. Initial characterisation of the tritium content of the sediment was completed 'as collected'. The sediment was freeze-dried in small batches. Approximately $200 \mathrm{~g}$ of ${ }^{3} \mathrm{H}$-contaminated dried sewage sludge pellets were sourced from Public Health England (PHE), UK. The pellets originated from an area in which contamination of the raw sludge feed-stock with TOM (along with ${ }^{14} \mathrm{C}$ ) was known to have occurred as a result of authorised aqueous discharges from a radiopharmaceutical manufacturing facility. The sludge pellets were ground using a tungsten carbide Tema ${ }^{\mathrm{TM}}$ mill, combined with approximately $1200 \mathrm{~g}$ of dry non-active sediment ('Dilution 1') and homogenised stepwise in a planetary mill proceeded by tumble mixing in a cement mixer with stainless steel ball-bearings. The tritium activity of Dilution-1 was determined by thermal desorption as per the initial characterisation. Leachable tritium activity was also determined by mixing an aliquot of the material with Milli- $\mathrm{Q}^{\mathrm{TM}}$ water for $24 \mathrm{~h}$ followed by analysis of a filtered ( $0.45 \mu \mathrm{m}$ syringe filter, Fisher Scientific) subsample of the leachate by LSC.

This article is protected by copyright. All rights reserved. 
Dilution-1 was autoclaved and the total and leachable tritium activities confirmed by analysis as previously. A further $800 \mathrm{~g}$ of non-active sediment was added to Dilution 1 and homogenised on a tumble mixer ('Dilution-2'). Large scale mixing of Dilution-2 with a further $15 \mathrm{~kg}$ of dry sediment was completed stepwise (in 2 kg increments) using a rotary drum cement mixer ('Dilution 3').

Characterisation of Dilution 3 indicated that further mixing was required in order to achieve the desired level of homogeneity. Dilution 3 was ground batch wise in a tungsten carbide Tema ${ }^{\mathrm{TM}}$ mill and recombined in the drum mixer for a further period of $20 \mathrm{~h}$. Final characterisation of randomly selected samples of the bulk sediment indicated sufficient homogeneity for use as an intercomparison material. The elemental composition of the material was determined by wavelength dispersive X-ray fluorescence spectrometry using a Philips Magix-Pro WDXRF instrument at the University of Southampton.

Extraction of ${ }^{3} \mathrm{H}$ in solid samples was performed using a Raddec Pyrolyser ${ }^{\mathrm{TM}}$ 6-trio combustion furnace (Raddec, Southampton, UK). A 6 hour ramp to $900{ }^{\circ} \mathrm{C}$ with, Pt-alumina catalyst was applied. Details of the extraction procedure have been published previously (Warwick et al. 2010, Croudace et al. 2017). The ${ }^{3} \mathrm{H}$ content in the combustion water was determined using a Wallac 1220 Quantulus Liquid Scintillation Counter ( $8 \mathrm{ml}$ aqueous sample and $12 \mathrm{ml}$ of Goldstar ${ }^{\mathrm{TM}}$ scintillation Cocktail, Meridian Ltd). The counter was calibrated using a quenched set of working calibration solutions prepared from a certified ${ }^{3} \mathrm{H}$ water calibration solution (Amersham, UK) traceable to primary measurement standards. The method is accredited to ISO/IEC 17025:2005. A reference date of $1^{\text {st }}$ June 2014 was set for decay correction of all analytical data. $\mathrm{A}^{3} \mathrm{H}$ half life of 12.33 years was used for correction of all characterisation measurements. The ${ }^{3} \mathrm{H}$ half life adopted by the participants was not specified or declared.

\section{Homogeneity and stability}

Nine sub-samples of the bulk material were taken for analysis prior to packaging. It is noted that the approach described in ISO13528-2015, was not strictly followed as sub-samples were taken from the bulk material prior to dispensing of the sample into individual bottles. Samples were analysed by two analysts using the combustion-based technique described previously.

Stability of the material was evaluated through repeat analysis following storage of the material. Triplicate analysis of the sample was performed 11 months after the original homogeneity test. A further replicate analysis $(n=6)$ was performed 30 months after the initial characterisation (following storage of the material at room temperature in sealed containers).

This article is protected by copyright. All rights reserved. 


\section{Distribution of proficiency test samples}

The characterised material was distributed to twenty-seven laboratories in nine countries. All laboratories were experienced in ${ }^{3} \mathrm{H}$ analysis of environmental matrices. Nominal $100 \mathrm{~g}$ aliquots of the sediment were sealed in new polythene bottles and assigned a unique identifier prior to despatch to participating laboratories. Laboratory 13 was unassigned. A reference date of 1st June 2014 was specified with all sub-samples dispatched.

A standard data reporting form was provided to all participants. Information requested including full contact details of the participating laboratory, procedure for sample preparation, details of the measurement system used, the sample bottle ID used, the sample masses analysed, results and associated uncertainties for each replicate analysis (reported as $\mathrm{Bq}^{-1}$ of combustion water and $\mathrm{Bq}$ $\mathrm{kg}^{-1}$ of sample), the mean and standard uncertainty of all results, the calculation equations used, raw count data and detection efficiencies and hydrogen content (for ${ }^{3} \mathrm{He}$-ingrowth measurements and conversion of $\mathrm{Bq} \mathrm{l}^{-1}$ to $\mathrm{Bq} \mathrm{kg}^{-1}$ ).

\section{Review of submitted proficiency test data}

All data received were assessed for obvious errors (blunder analysis). Any obviously deviant datasets were rejected. The remaining data (excluding late submissions) were assessed for normal distribution by visual inspection of a ranked data plot.

\section{Calculation of assigned value}

The assigned value for the proficiency test was calculated based on a consensus value from all participating laboratories (excluding data removed via blunder analysis and late submissions). A robust statistical technique based on winsorization was used to censor the dataset and determine the robust mean, $x_{p t}$, standard deviation of the robust mean, $s_{p t}^{*}$ and standard uncertainty, $u\left(x_{p t}\right)$ for the dataset. Algorithm A (as defined in ISO13528) was used to determine the robust statistics for the dataset. The robust mean and standard deviation were calculated using the mean result of replicate data reported for each laboratory. The robust mean was taken as the assigned value for the proficiency test.

\section{Assessment of performance}

The performance of each laboratory was assessed using the criteria in Table 1. For percentage deviation and uncertainty assessment, results were deemed as either in agreement (pass) or discrepant (fail). For all other performance parameters, data were designated as either 'pass', 'check' or 'fail, as defined in Table 1.

This article is protected by copyright. All rights reserved. 


\section{Results and discussion}

\section{Characterisation of starting material}

The ${ }^{3} \mathrm{H}$ activity per unit mass and associated standard uncertainty of the sewage sludge and marine sediment (a mud containing finely comminuted quartz, clays and carbonate minerals) were measured as $(7.1 \pm 0.7) \times 10^{4} \mathrm{~Bq} \mathrm{~kg}^{-1}$ and $8 \pm 3 \mathrm{~Bq} \mathrm{~kg}^{-1}$ respectively (reference date $1^{\text {st }}$ June 2014; all standard uncertainties are reported with coverage factor, $\mathrm{k}=1$ ). Following mixing, the activity per unit mass of dilution- 1 was measured as $14,700 \pm 1600 \mathrm{~Bq} \mathrm{~kg}^{-1}$. Autoclaving the material resulted in negligible loss of ${ }^{3} \mathrm{H}$. Leachable ${ }^{3} \mathrm{H}$ was estimated as $25 \%$ prior to autoclaving and $21 \%$ after autoclaving. Following a further two dilution stages and homogenisation, the activity per unit mass, was determined as $174 \pm 10 \mathrm{~Bq} \mathrm{~kg}^{-1}(n=9)$. The major elemental composition (expressed as the oxide) of the final dilution was $\mathrm{SiO}_{2}(62.1 \%), \mathrm{Al}_{2} \mathrm{O}_{3}(15.8 \%), \mathrm{Fe}_{2} \mathrm{O}_{3}(5.8 \%), \mathrm{CaO}(3.5 \%), \mathrm{MgO}(3.4 \%)$, $\mathrm{K}_{2} \mathrm{O}(3.3 \%), \mathrm{Na}_{2} \mathrm{O}(1.4 \%), \mathrm{TiO}_{2}(0.95 \%), \mathrm{S}(0.91 \%), \mathrm{Cl}(0.89 \%) \mathrm{P}_{2} \mathrm{O}_{5}(0.13 \%), \mathrm{MnO}(0.07 \%)$ and $\mathrm{Sr}$ (0.012\%).

\section{Homogeneity and stability}

The mean activity per unit mass and standard uncertainty for replicate analyses was $174 \pm 10 \mathrm{~Bq} \mathrm{~kg}^{-1}$ $(\mathrm{k}=1)$. ISO13528-2015 states that the between-sample standard deviation of the replicate analysis performed as part of the homogeneity check must be less than $0.3 \mathrm{~s}_{\mathrm{pt}}{ }^{*}$, which is equal to $4 \mathrm{~Bq} \mathrm{~kg}{ }^{-1}$. However, $s_{p t}^{*}$ is the robust standard deviation of the participants' data and will therefore include the uncertainty associated with sample inhomogeneity. No further consideration of sample homogeneity was therefore made when assessing performance.

The decay-corrected mean activity per unit mass and associated standard uncertainty of the second analysis (after 11 months) was $171 \pm 12 \mathrm{~Bq} \mathrm{~kg}^{-1}(\mathrm{k}=1)$. The difference between the mean activity per unit mass of the first and second analysis set is $3 \mathrm{~Bq} \mathrm{~kg}^{-1}$ which is less than the $0.3 \mathrm{~s}^{*}{ }_{\mathrm{pt}}$ value of $4 \mathrm{~Bq}$ $\mathrm{kg}^{-1}$. The material was therefore considered to be stable for the purposes of the proficiency test. The decay-corrected mean activity per unit mass and associated standard uncertainty of the third measurement (after 30 months) was $180 \pm 11 \mathrm{~Bq} \mathrm{~kg}^{-1}(\mathrm{k}=1)$ which is in good agreement with the original value and demonstrates that the material has remained stable over a storage period of 30 months.

Long term stability was evaluated in consideration of the on-going use of the material over a 10 year period following the proficiency test exercise based on the approach detailed in ISO Guide 35:2017. Repeated analysis of the material over a 30 month period did not indicate a systematic decline in the activity per unit mass. The standard uncertainty contribution from long sample instability, $u_{\mathrm{lts}}$, was therefore calculated using the procedure recommended for scenarios where there is no systematic trend. The rate of change was estimated using a linear regression analysis of the measured activity per unit mass over time. Based on the linear regression analysis, the standard error on the gradient,

This article is protected by copyright. All rights reserved. 
$s\left(b_{1}\right)$ was calculated as $2.2 \mathrm{~Bq} \mathrm{~kg}^{-1} \mathrm{y}^{-1}$. The uncertainty associated with long-term stability was then calculated using Equation (1):

$$
u_{\text {Its }}=s\left(b_{1}\right)\left(t_{m 1}+t_{c e r t}\right)
$$

where $t_{m 1}$ is the time interval between value assignment and initial stability monitoring point and $t_{\text {cert }}$ is the period of validity (ISO 2017). For a 10 year period of validity, $u_{\mathrm{lts}}=22 \mathrm{~Bq} \mathrm{~kg}^{-1}$. This uncertainty was combined with the standard uncertainty of the assigned value determined for the proficiency test to give the combined standard uncertainty on the certified value for the reference material.

\section{Data submission}

Nineteen laboratories originally submitted datasets (Table 2). Of these, one dataset was submitted after the deadline and was excluded from the statistical analysis and two datasets were rejected as being erroneous (blunder analysis). Sixteen datasets comprising of eighty-three individual measurements were accepted for further analysis and calculation of the assigned value for the sample. Three datasets were received after the exercise deadline but before release of data on the assigned value (including two revised datasets from laboratories that had previously reported erroneous data). These datasets were excluded from the statistical analysis but have been included in the laboratory performance assessment.

A range of analytical techniques was used for ${ }^{3} \mathrm{H}$ extraction including tube furnace (eleven laboratories), commercial oxidiser (four laboratories) and oxygen bomb combustion (one laboratory). Helium-3 ingrowth was used by three laboratories. For oxygen bomb combustion, naphtha was used as a combustion aid. Measurement of ${ }^{3} \mathrm{H}$ was either by liquid scintillation counting (Wallac / Perkin Elmer 1220 Quantulus, Perkin Elmer 2900, 3170 or 3180 or Aloka LB5 counters) or noble gas mass spectrometry (for ${ }^{3} \mathrm{He}$-ingrowth measurements). For liquid scintillation measurements, a range of scintillation cocktails (Perkin Elmer Ultima Gold ${ }^{\circledR}$ LLT / Monophase ${ }^{\circledR} S$ or Meridian Gold Star) were used and efficiencies were typically determined through the use of quench curves or via internal standardisation. Plastic vials were generally used, with one laboratory using PTFE-lined vials and one laboratory using Teflon vials.

Five laboratories reported $\mathrm{H}$ content in the intercomparison sample based on the mass of water generated by combustion (four laboratories) or via an unspecified approach (one laboratory). There was a wide spread of results, with reported $\mathrm{H}$ weight percentages ranging from 0.55 to $1.2 \mathrm{wt} \%$. The mean hydrogen content and associated standard deviation was $0.79 \pm 0.21 \mathrm{wt} \%$.

This article is protected by copyright. All rights reserved. 


\section{Visual inspection of data}

A ranked plot of all data (excluding late submissions and rejected data) indicated a symmetrical, unimodal distribution consistent with a normal distribution of data (Figure 2). Seven of the 83 individual reported results were considered as outliers (red points). The percentage of outliers $(8.4 \%)$ is within the $<20 \%$ target specified in ISO13528-2015, permitting the use of winsorisation to determine a robust mean and standard deviation of the dataset.

\section{Consideration of variations arising from techniques}

Datasets were grouped into five categories of techniques, namely He ingrowth, Pyrolyser ${ }^{\mathrm{TM}}$ tube furnace (open tube, thermal combustion system as used in the initial characterisation of the material), other non-proprietary tube-based furnaces, Perkin Elmer Oxidiser (an open system flame combustion technique) and oxygen combustion bomb (rapid combustion in an excess oxygen closed system). No significant differences in the reported activity per unit masses were observed in the datasets arising from the different techniques (Figure 3). All data agreed with the initial activity per unit mass estimate obtained during the homogeneity test. It was noted that the standard deviation associated with data arising from the oxidiser was large compared with the other techniques, probably reflecting the small sample sizes taken for analysis.

\section{Determination of assigned value}

A winsorization approach was used to censor the datasets, resulting in two datasets being considered as outliers. Convergence was obtained after one iteration of the winsorization process. The arithmetic mean of all data, the mean excluding outliers, the median and the robust mean are all in good agreement (Table 3 ). The calculated standard uncertainty, $u\left(x_{\mathrm{pt}}\right)$, for the proficiency test is comparable to $0.3 \mathrm{~s}^{*}$ and is therefore not included in the interpretation of the performance data. The assigned value for the proficiency test and associated standard uncertainty of $168 \pm 4 \mathrm{~Bq} \mathrm{~kg}^{-1}(\mathrm{k}$ $=1$ ) is also in good agreement with the initial characterisation value of $174 \pm 10 \mathrm{~Bq} \mathrm{~kg}^{-1}$.

\section{Performance assessment}

In total, nineteen laboratories submitted data to the proficiency test (Lab No. 13 was unassigned) (Figures 4 and 5).

< Figure 4 >

$<$ Figure $5>$

This article is protected by copyright. All rights reserved. 
Performance was assessed based on the percentage deviation, the $z$-score, the zeta score and the reported standard uncertainties. Two laboratories (labs 11 and 18) reported data that were outside the acceptance range for percentage deviation, with one laboratory biasing high and one biasing low (Figure 6a). In both instances, the laboratories were using an oxidiser system (Perkin Elmer).

$<$ Figure $6>$

Laboratories 11 and 18 were also considered discrepant based on a z score greater than 3 (Figure $6 \mathrm{~b})$. In addition, one dataset (lab 9) was categorised in the 'check' category with a $z$-score between 2 and 3. In terms of zeta score, two laboratories (lab 9 and 18) were considered as discrepant (Figure $6 c)$. The high zeta score for lab 9 reflects a very low reported uncertainty on the measured value. In addition one zeta scores (lab 11) was categorised as 'check'. This related to a high percentage deviation of the reported activity per unit mass from the assigned value.

The standard uncertainties $(\mathrm{k}=1)$ reported by three laboratories were outside of the defined range for acceptance (Figure 6d). In one instances (lab 14), the reported uncertainties were less that the $u\left(x_{\mathrm{pt}}\right)$ value, with data obtained via He-ingrowth. In the other instances, the reported uncertainties were greater than 1.5 times the standard deviation of the reported dataset, with both measurements performed using an oxidiser system.

\section{Certified value for the reference material}

Following the proficiency test, the material has been made available as a natural matrix reference material. The assigned value for the proficiency test, $x_{p t}$, was taken as the reference material, $x_{\text {ref, }}$ activity per unit mass. The associated standard uncertainty, $u\left(x_{\text {ref }}\right)$ was calculated, taking into account the stability of the material over extended time periods of up to 10 years, by combining the standard uncertainty on the assigned value, $u\left(\mathrm{x}_{\mathrm{pt}}\right)$, with the standard uncertainty associated with long term stability, $u_{\text {lts }}$. The reference value for the natural matrix reference material is $168 \pm 22 \mathrm{~Bq} \mathrm{~kg}^{-1}(\mathrm{k}=1)$.

\section{Conclusions}

A chemically-stable TOM-sediment reference material, selected to have long-term resilience, has been prepared by diluting sewage sludge containing TOM derived from radiopharmaceutical byproducts with normal muddy marine sediment. This sewage sludge containing TOM components has resulted in a chemically resilient form of ${ }^{3} \mathrm{H}$ which has persisted through the waste treatment process (having lost volatile / unstable components) and which contains a range of tritium organic molecule species. The choice of material has been underpinned by fundamental study of its

This article is protected by copyright. All rights reserved. 
behaviour in the marine environment, which indicated its long-term stability. The autoclaved NMRM has been demonstrated to be stable under laboratory conditions after repeated testing over 30 months. The NMRM has been thoroughly characterised through an interlaboratory comparison exercise with excellent agreement being observed between all participating laboratories across a range of analytical techniques. A reference value and standard uncertainty of $168 \pm 22 \mathrm{~Bq} \mathrm{~kg}^{-1}(\mathrm{k}=1)$ on 1st June 2014 has been determined for the NMRM based on a consensus value of all participating laboratories. The sediment NMRM is suitable for on-going method development, validation and quality control and will help to support more robust measurement of ${ }^{3} \mathrm{H}$ in environmental matrices. Along with other NMRMs produced as part of the International Organically Bound Tritium Working Group and related programmes, the material will address the identified need for well-characterised and relevant TOM NMRMs that are required to underpin analytical quality.

\section{Acknowledgements}

The authors would like to thank Leon Ewer (Public Health England, Didcot, UK) for supplying the sewage sludge derived from the Cardiff East Waste Water Treatment Works and Andrew Pearce (National Physical Laboratory) for useful discussions regarding terminology. Note that the two lead authors were responsible for the design and development of one of the instruments used in the intercomparison.

\section{References}

Baglan N., Kim S.B., Cossonnet C., Croudace I.W., Fournier M., Galeriu D., Warwick P.E., Momoshima N. and Ansoborlo E. (2013)

Organically bound tritium (OBT) behaviour and analysis: Outcomes of the seminar held in Balarucles-Bains in May 2012. Radioprotection, 48, 127-144.

Baglan N., Kim S.B., Cossonnet C., Croudace I.W., Fournier M., Galeriu D., Warwick P.E., Momoshima N. and Ansoborlo E. (2015)

Organically-bound tritium analysis in environmental samples. Fusion Science \& Technology, 67, 250-253.

Croudace I., Warwick P.E. and Marsh R. (2017)

This article is protected by copyright. All rights reserved. 
A suite of robust radioanalytical techniques for the determination of tritium and other volatile radionuclides in decommissioning wastes and environmental matrices. Fusion Science \&

Technology, 71, 290-295.

Croudace I.W., Warwick P.E. and Morris J.E. (2012)

Evidence for the preservation of technogenic tritiated organic compounds in an estuarine sedimentary environment. Environmental Science \& Technology, 46, 5704-5712.

DeVol T.A. and Powell B.A. (2004)

Theoretical organically-bound tritium dose estimates. Health Physics, 86, 183-186.

Diabaté S. and Strack S. (1993)

Organically-bound tritium. Health Physics, 65, 699-712.

ISO13528-2015

Statistical methods for use in proficiency testing by interlaboratory comparison. International Organization for Standardization (Geneva, Switzerland).

\section{ISO17025:2005}

General requirements for the competence of testing and calibration laboratories. International Organization for Standardization (Geneva, Switzerland).

\section{ISO Guide 35:2017}

Reference materials - Guidance for characterization and assessment of homogeneity and stability. International Organization for Standardization (Geneva, Switzerland).

Kim D-J, Warwick P.E. and Croudace I.W. (2008)

Tritium speciation in nuclear reactor bioshield concrete and its impact on accurate analysis.

Analytical Chemistry, 80, 5476-5480. 
Kim S.B., Baglan N. and Davis P.A. (2013)

Current understanding of organically bound tritium (OBT) in the environment. Journal of

Environmental Radioactivity, 126, 83-91.

Kim S.B., Olfert J., Baglan N., St-Amant N., Carter B., Clark I. and Bucur C. (2015)

Canadian inter-laboratory organically bound tritium (OBT) analysis exercise. Journal of

Environmental Radioactivity, 150, 236-241.

Warwick P.E., Kim D., Croudace I.W. and Oh J-S. (2010)

Effective desorption of tritium from diverse solid matrices and its application to routine analysis of decommissioning materials. Analytica Chimica Acta, 676, 93-102.

\section{Figure captions}

Figure 1. Summary of sediment preparation and characterisation.

Figure 2. Ranked distribution of all data (excluding late submissions and rejected data). Outliers are shown by open symbols.

Figure 3. Comparison of data obtained using differing techniques (including outliers). Vertical bars represent the standard deviation of the measured values. Dotted line represents the initial activity per unit mass determined by the organising laboratory using a pyrolyser.

Figure 4. Summary of proficiency test data by laboratory. Vertical bars represent the reported standard uncertainty of the measured values $(k=1)$. The range refers to the $x_{p t} \pm 3 s^{*}$.

Figure 5. Ranked data identified by technique used. Vertical bars represent the reported standard uncertainty of the measured values $(k=1)$. The range refers to the $x_{p t} \pm 3 s^{*}$.

This article is protected by copyright. All rights reserved. 
Figure 6. Laboratory data evaluation. (a) \% deviation; (b) z-score; (c) zeta score; (d) laboratory reported standard uncertainty. Points shown in white represent discrepant (fail) data, grey points represent questionable (check) data.

Table 1.

Criteria for assessment of laboratory performance

\begin{tabular}{|l|l|l|}
\hline Criterion & Calculation & Pass criteria \\
\hline Percentage deviation, $D_{i}$ & $D_{i}=\frac{\left(x_{i}-x_{p t}\right)}{x_{p t}} \times 100$ & $\left(\mathrm{x}_{\mathrm{pt}}+3 \mathrm{~s}^{*}\right)>\mathrm{x}_{\mathrm{i}}>\left(\mathrm{x}_{\mathrm{pt}}-3 \mathrm{~s}^{*}\right)$ \\
\hline Z score, $z$ & $z=\frac{\left(x_{i}-x_{p t}\right)}{s^{*}}$ & $\begin{array}{l}|\mathrm{z}|<2 \quad-\text { PASS } \\
2<|\mathrm{z}|<3-\text { CHECK } \\
|z|>3 \quad-\text { FAIL }\end{array}$ \\
\hline Zeta score, $\zeta_{i}$ & $\zeta_{i}=\frac{\left(x_{i}-x_{p t}\right)}{\sqrt{u^{2}\left(x_{i}\right)+u^{2}\left(x_{p t}\right)}}$ & $\begin{array}{l}2<|\zeta|<3-\text { CHECK } \\
|\zeta|>3 \quad-\text { FAIL }\end{array}$ \\
\hline Uncertainty, $u\left(x_{\mathrm{i}}\right)$ & $\underline{u}_{\min }=\mathrm{u}\left(\mathrm{x}_{\mathrm{pt}}\right)$ & $u_{\min }<u\left(\mathrm{x}_{\mathrm{i}}\right)<u_{\max }$ \\
& $u_{\max }=1.5 s^{*}$ & \\
\hline
\end{tabular}

This article is protected by copyright. All rights reserved. 
Table 2.

List of laboratories providing data

\begin{tabular}{|c|c|}
\hline Laboratory & Country \\
\hline CNL, Chalk River Laboratories Ontario & CANADA \\
\hline Canadian Nuclear Safety Commission, Ottawa & CANADA \\
\hline CEA Valduc & FRANCE \\
\hline EDF / CEIDRE / DLAB Chinon, & FRANCE \\
\hline IRSN Orsay, & FRANCE \\
\hline LSCE - Orme des Merisers & FRANCE \\
\hline SUBATECH, Nantes & FRANCE \\
\hline Bhabba ARC Environmental Survey Laboratory Maharashtra & INDIA \\
\hline Bhabba ARC, Environmental Survey Laboratory, MAPS Tamilnadu & INDIA \\
\hline $\begin{array}{l}\text { Institute for Environmental Sciences, Dept of Radioecology, Rokkasho, } \\
\text { Aomori }\end{array}$ & JAPAN \\
\hline Radioisotope Center, Kyushu University Fukuoka & JAPAN \\
\hline Institute of Radiation Safety and Ecology NNC RK (IRBE) & KAZAKHSTAN \\
\hline Environmental Radioactivity Assessment Team, KAERI Daejeon, & KOREA \\
\hline Cernovoda NPP, Environmental control laboratory & ROMANIA \\
\hline \multicolumn{2}{|l|}{ ICIT National Institute of Cryogenics and Isotopic Technologies Tritium } \\
\hline Laboratory & ROMANIA \\
\hline HEPIA, Laboratoire de chimie nucléaire Genève, & SWITZERLAND \\
\hline AMEC Analytical Services & UK \\
\hline AWE Aldermaston & UK \\
\hline GAU-Radioanalytical, University of Southampton Southampton & UK \\
\hline
\end{tabular}

This article is protected by copyright. All rights reserved. 
Table 3.

Summary of data for determination of the assigned value for the proficiency test and reference value for subsequent use

\begin{tabular}{|c|c|c|c|}
\hline Approach & Value $\left(\mathrm{Bq} \mathrm{kg}{ }^{-1}\right)$ & $\begin{array}{l}\text { Standard } \\
\text { deviation } \sigma\left(x_{p t}\right) \\
\text { or } s_{p t}^{*}\end{array}$ & $\begin{array}{l}\text { Standard } \\
\text { uncertainty } \\
u\left(\mathrm{x}_{\mathrm{pt}}\right)\end{array}$ \\
\hline $\begin{array}{l}\text { Arithmetic mean } \\
\text { (all data) }\end{array}$ & 168 & 24 & \\
\hline $\begin{array}{l}\text { Arithmetic mean } \\
\text { (excluding } \\
\text { outliers) }\end{array}$ & 169 & 18 & \\
\hline $\begin{array}{l}\text { Median, } \\
\text { MADe(x) (nIQR) }\end{array}$ & 167 & $13(13)$ & \\
\hline $\begin{array}{l}\text { Robust mean, } \\
\text { standard } \\
\text { deviation and } \\
\text { standard } \\
\text { uncertainty for } \\
\text { proficiency test } \\
\text { (Algorithm A) }\end{array}$ & 168 & 14 & $\begin{array}{l}4 \\
(p=16)\end{array}$ \\
\hline $\begin{array}{l}\text { Assigned values } \\
\text { for proficiency } \\
\text { test }\end{array}$ & & & \\
\hline $\begin{array}{l}\text { Reference value } \\
\text { for RM }\end{array}$ & 168 & & 22 \\
\hline
\end{tabular}

This article is protected by copyright. All rights reserved. 

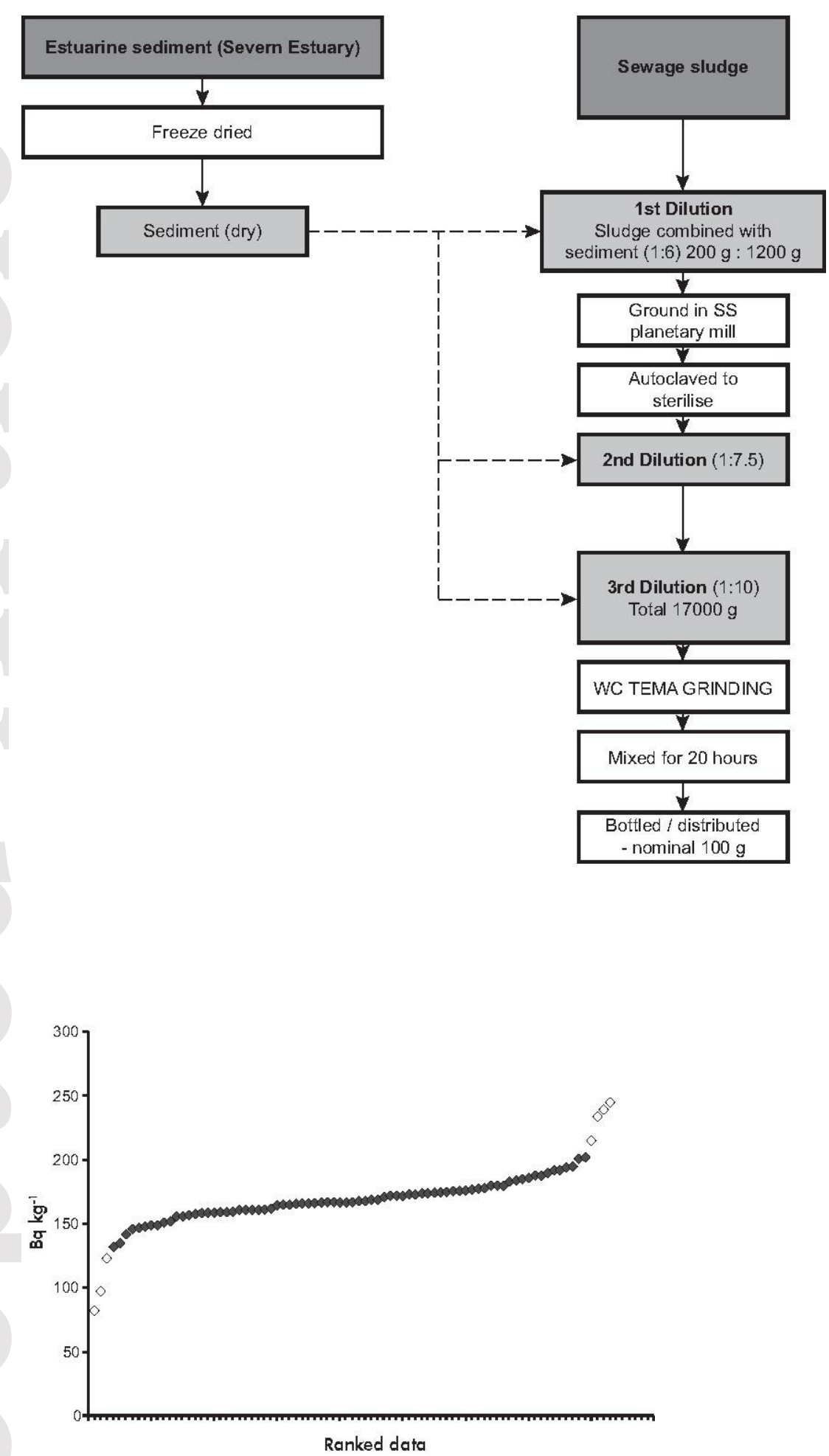

This article is protected by copyright. All rights reserved. 

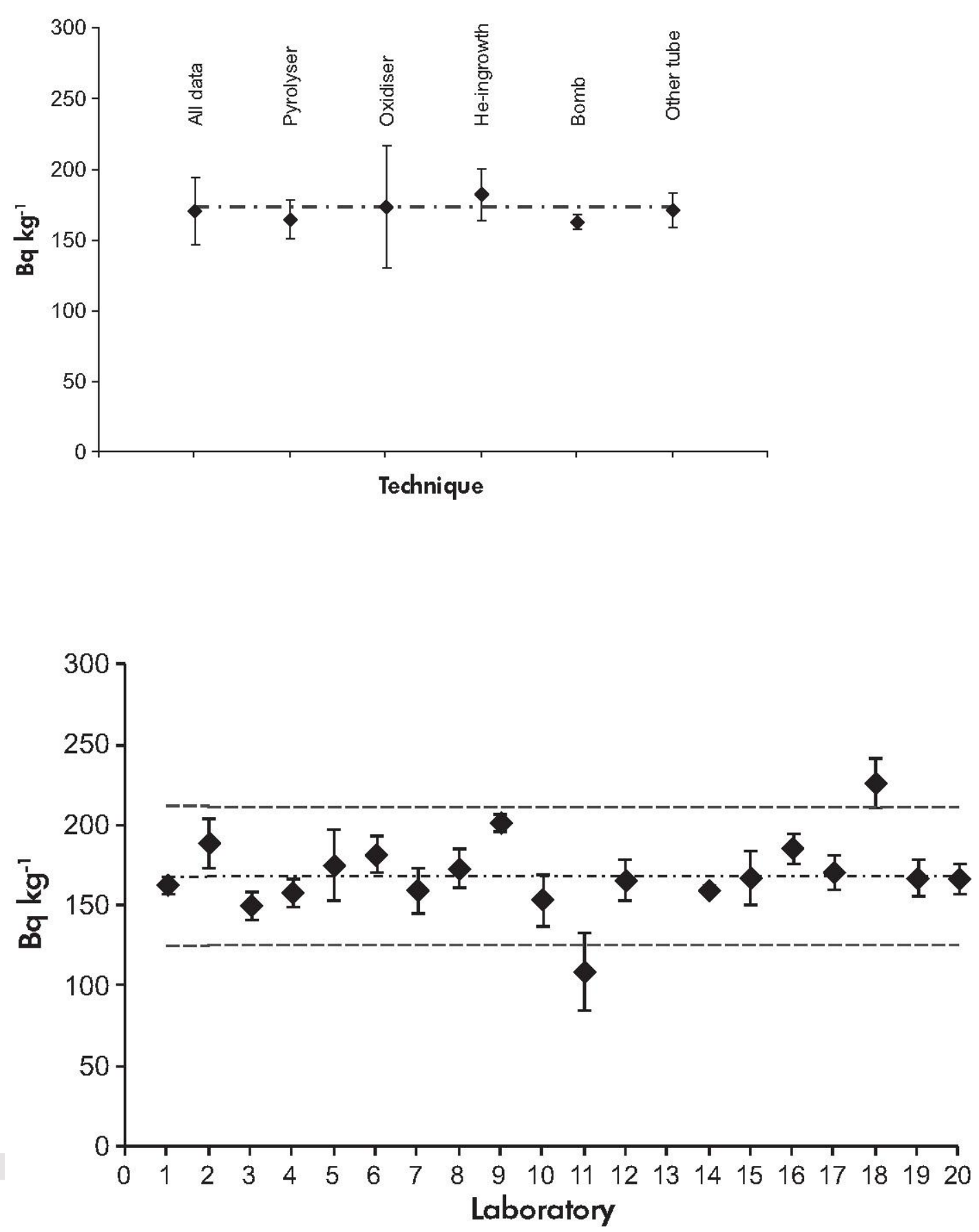

This article is protected by copyright. All rights reserved. 

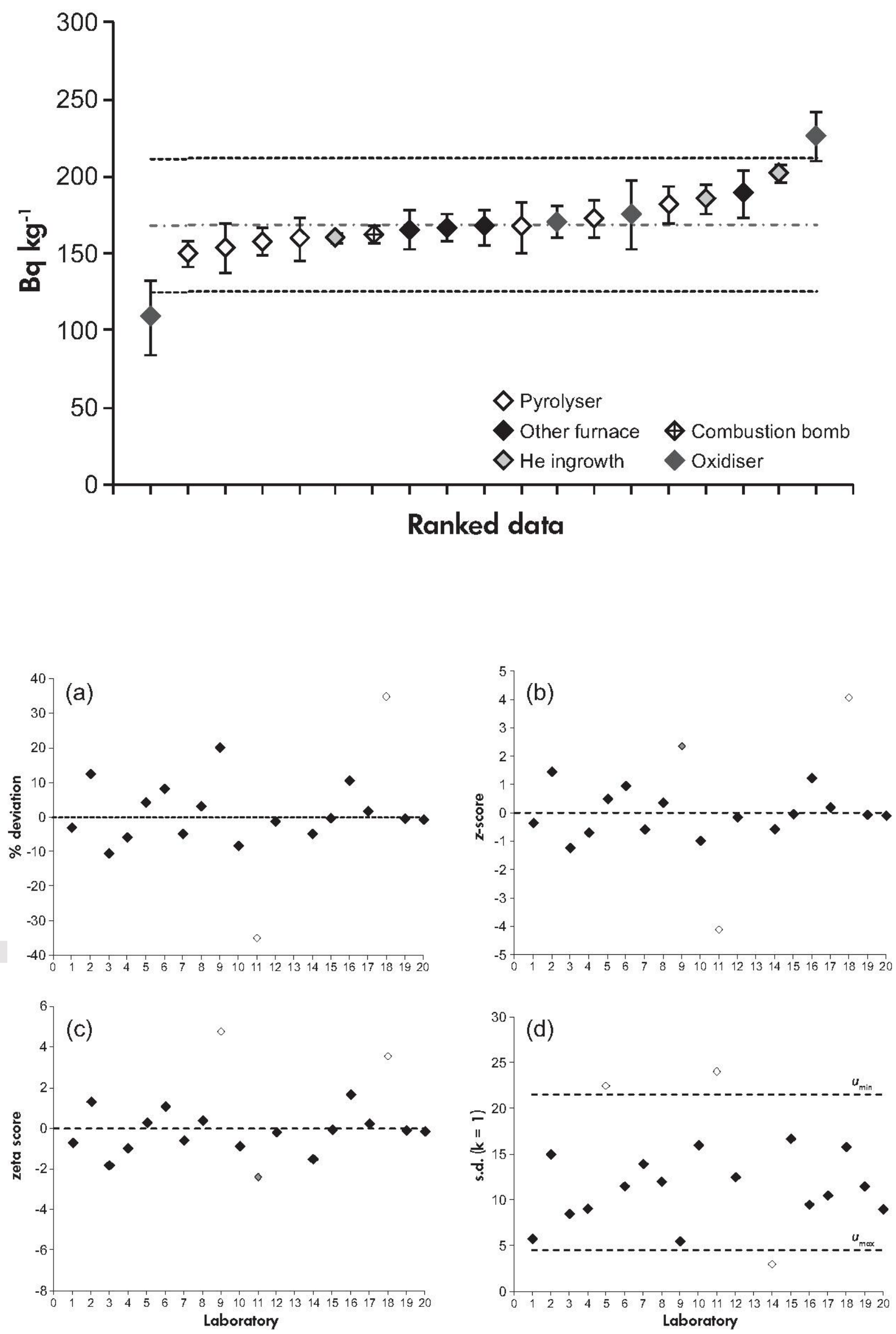

This article is protected by copyright. All rights reserved. 